\title{
Workshop on Personal and Pervasive Fabrication (PerFab 2013)
}

\section{Manfred Lau}

Lancaster University

m.lau@lancaster.ac.uk

Christian Weichel

Lancaster University

c.weichel@lancaster.ac.uk

Nicolas Villar

Microsoft Research Cambridge

nvillar@microsoft.com

Permission to make digital or hard copies of all or part of this work for personal or classroom use is granted without fee provided that copies are not made or distributed for profit or commercial advantage and that copies bear this notice and the full citation on the first page. Copyrights for components of this work owned by others than ACM must be honored. Abstracting with credit is permitted. To copy otherwise, or republish, to post on servers or to redistribute to lists, requires prior specific permission and/or a fee. Request permissions from permissions@acm.org.

UbiComp'13 Adjunct, September 8-12, 2013, Zurich, Switzerland.

Copyright (c) 2013 ACM 978-1-4503-2139-6/13/09...\$15.00.

http://dx.doi.org/10.1145/2494091.2499210

\begin{abstract}
Recently, technologies for fabricating real-world objects and products that can be designed and built directly by the end-user have decreased in costs and are

increasingly common. These technologies are expected to have a great impact on society and the persona fabrication concept has been described as the "new or third industrial revolution". However, there is a great need to explore many novel research challenges and issues before the idea of personal fabrication becomes truly pervasive and applicable to the wider public.

PerFab is a workshop for providing a forum to bring together researchers from various disciplines working in this area. We intend to identify, explore and contribute to the research challenges that will allow personal fabrication to be pervasive. We will invite paper submissions to our workshop, review the submissions with a peer review process, and include the accepted papers in the ACM Digital Library. The long-term goal is to gather a community of researchers and establish this workshop as a leading forum for research dissemination in the area.
\end{abstract}

\section{Author Keywords}

Personal Fabrication; Geometric Modeling; User Interfaces; User-generated Design; Rapid Prototyping;

Customization 


\section{ACM Classification Keywords}

H.5 [Information Interfaces and Presentation (HCI)];

I.3 [Computer Graphics]; 1.6 [Computer-Aided

Engineering]

\section{Topic of Workshop}

The focus of the workshop is on personal fabrication and the challenges that need to be overcome to make it pervasive. Personal fabrication is in contrast to mass production. Instead of buying pre-designed and prebuilt products (as in mass production), individuals are empowered with the ability to design, customize, and fabricate personalized products by themselves and in their own home. This personal fabrication concept $[1,2]$ has been described as the "new or third industrial revolution" $[3,4]$. It can transform multiple industries and lead to major paradigm shifts in the way products are designed, manufactured, stored, transported, and consumed.

Rapid prototyping technologies such as 3D printers and laser cutters are becoming more common and accessible. Their costs have been gradually decreasing such that a MakerBot 3D printer, for example, is affordable to the average consumer for use at home. However, for the concept of personal fabrication to be fully realized and be truly pervasive in reaching and impacting the life of a layperson, many research topics and issues need to be explored.

Research from various disciplines are applicable to our workshop, including (but not limited to): graphics and visualization, geometry modeling, human-computer interaction, user interfaces, computational design, fabrication, and rapid prototyping.
A more specific list of topics of interest includes, but are not limited to:

- user interfaces for designing fabricatable objects

- geometric modeling tools for fabrication

- fabrication-aware analysis of 3D models

- computational design of objects that takes fabrication constraints into account

- rapid prototyping technologies that are novel and low-cost

- application of personal fabrication for specific domains (e.g. designing and/or building furniture, jewelry)

- new materials for fabrication

- crowd sourcing for designing fabricatable objects

- representation and visualization of physically realizable objects

- $\quad$ simulation of physically realizable objects

\section{Rationale of Workshop}

Fabricating real-world objects with prototyping technologies such as 3D printers and laser cutters has recently attracted the attention of researchers from various academic communities. In addition, the concept of personal fabrication is expected to have a significant societal impact in the near future. We discuss both the academic and societal impacts of potential research work in fabrication, and thereby the need to organize this workshop to bring together researchers and consolidate work done in this area. 
We also discuss the relevance of our topic to the UbiComp conference.

\section{Academic Impact}

There have recently been many strong and interesting publications related to fabrication in various research communities. Such publications have appeared in the computer graphics community [5-10], humancomputer interaction community [11-14], tangible user interfaces community [15-17], and computational design community [18-20]. These publications are only a subset of examples, and it is evident that more work is currently being performed and will continue to appear in these communities in the near future. While the work in these different research communities may sometimes overlap, the researchers in these fields may not be aware of each other's work. Hence there is a need to consolidate these research areas and bring together researchers in different communities with our proposed workshop.

\section{Societal Impact}

The development of personal fabrication as a field will have an impact on multiple industries and the wider public. The 3D/CAD (computer-aided design) modeling software industries will benefit, for example, if more user interfaces and modeling tools that a non-technical person can use are available. The rapid prototyping and fabrication industries can benefit with a better understanding of the end-user's needs and preferences in the use of fabrication technologies. As the design and manufacturing of products can become

fundamentally different, the transport and energy sectors will be affected. The ultimate beneficiary is the wider public. Personalized products are customized to fit with each individual, and the utility and enjoyment from using such products are higher. The goal of our workshop from the societal point of view is to apply fabrication technologies and tools to everyday realworld scenarios, and bring such technologies from research labs/offices into people's homes.

\section{Soliciting Research Contributions}

Based on these academic and societal impacts, we will organize this workshop to provide a forum for sharing research in this area. We solicit original research contributions for inclusion in the ACM Digital Library and the supplemental proceedings of the conference. We have a peer-review process for the submitted papers by a committee of international experts. The workshop itself is open to all who wish to attend, and there is no limit in the workshop attendance.

Relevance of Workshop Topic to UbiComp Conference Prototyping technologies such as 3D printers and laser cutters are gradually decreasing in prices and are increasingly common in research labs/offices.

However, they are still not commonly used in people's homes. This may be because such technologies are difficult to use, in particular for those with no computing or technical background. Potential users may not know what products to design and fabricate, and how to design them. An underlying theme of the list of topics in the first section is to allow such technologies to become common and ubiquitous to an end-user's daily life. In this sense, our workshop topic is relevant to and will enrich the UbiComp conference.

\section{Objectives of Workshop}

The objectives of our proposed workshop are: 
- to bring together researchers from various disciplines who work in and/or are interested in the personal fabrication area

- to consolidate research among separate disciplines and provide one forum for research dissemination

- to identify major research challenges in personal fabrication and in allowing it to be pervasive

- to generate useful results and discussions to move the field forward

- to establish a community of researchers, and potential links for future collaborations

\section{Organizers' Background}

Manfred Lau is an Assistant Professor (Lecturer in UK) in the School of Computing and Communications at Lancaster University, United Kingdom. His research interests include computer graphics, sketch-based modeling, and tangible user interfaces. Manfred received his $\mathrm{PhD}$ degree in Computer Science from Carnegie Mellon University.

Christian Weichel is a PhD student at the School of Computing and Communications at Lancaster University UK, under the supervision of Hans Gellersen. His research interests lie at the intersection of personal fabrication and human computer interaction, particularly tangible user interfaces and computational design. Christian received his Bachelor of Science from Hochschule Furtwangen University, Germany.

Nicolas Villar is a researcher at Microsoft Research, based in Cambridge, UK. His involvement in the area of personal fabrication includes the development of .NET Gadgeteer - a toolkit that combines modular hardware, object-oriented software and CAD modeling to enable the rapid development of embedded devices. More generally, his research interests include tangible and embedded interaction, and the use of embedded and sensing technologies to enable novel interactive experiences. He is on the steering committee of the ACM TEI series of conferences.

\section{Detailed Plan}

\section{Submissions}

The submissions can either be short papers with a maximum length of four pages or full papers with a maximum length of eight pages. We encourage submissions of research papers, work-in-progress papers with interesting preliminary results that can lead to more future work, and position papers. All submissions should be in the SIGCHI archival format (double column, PDF).

All submitted papers are reviewed by at least two members of the program committee. If authors would like to cite their previous research in their submissions, they should do so by referring to themselves in the third person. Submissions should not contain any proprietary or confidential information at the time of publication. Submitted papers cannot be previously published or be under simultaneous review for other conferences, journals, or workshops.

Accepted papers are published in the ACM Digital Library and the UbiComp 2013 conference supplemental proceedings, if at least one of the authors registers for the conference and attends the workshop to present the paper. 
Pre-Workshop Approximate Timeline:

- April 19: Distribution of Call for Papers, publicize workshop with CFP via UbiComp website and email, and encourage potential participants to submit papers

- June 1: Paper submission deadline

- June 19: Notification of accepted papers

- June 30: Camera-ready version of workshop papers due

\section{References}

[1] Gross M. Now more than ever: computational thinking and a science of design. Japan Society for the Science of Design, 16, 2 (2007), 50-54.

[2] Landay J. Design tools for the rest of us. Communications of the ACM, 52(12), 2009, 80.

[3] Wired UK. Atoms are the new bits - the new industrial revolution. February 2010.

[4] The Economist. The third industrial revolution. April 2012.

[5] Lau M., Ohgawara A., Mitani J., Igarashi T. Converting 3D Furniture Models to Fabricatable Parts and Connectors. ACM Transactions on Graphics (SIGGRAPH), 30, 4 (2011), Article No. 85.

[6] Lau M., Mitani J., Igarashi T. Digital Fabrication. IEEE Computer Magazine, December 2012, pp. 76-79.

[7] Bacher M., Bickel B., James D., Pfister H. Fabricating articulated characters from skinned meshes. ACM Transaction on Graphics (SIGGRAPH), 31, 4 (2012), Article No. 47.

[8] Zhu L., Xu W., Snyder J., Liu Y., Wang G. Guo B. Motion-guided mechanical toy modeling. ACM

Transactions on Graphics (SIGGRAPH Asia), 31, 6 (2012), Article No. 127.
- September 9: Day of workshop

Post-Workshop Follow Up

- Thank participants for attending workshop through mailing list (established during workshop), and keep them aware of mailing list which will continue to exist after workshop

- $\quad$ Add list of workshop attendees to website

- Add presentations and slides to website, and add links to papers in ACM Digital Library

[9] Cali J., Calian D., Amati C., Kleinberger R., Steed A., Kautz J., Weyrich J. 3D-printing of non-assembly, articulated models. ACM Transaction on Graphics (SIGGRAPH Asia), 31, 6 (2012), Article No. 130.

[10] Schwartzburg Y. and Pauly M. Fabrication-aware Design with Intersecting Planar Pieces. Eurographics 32, 2 (2013).

[11] Villar N., Scott J., Hodges S., Hammil K., Miller C. .NET Gadgeteer: A Platform for Custom Devices. International Conference on Pervasive Computing, June 2012.

[12] Johnson G., Gross M., Do E., Hong J. Sketch It, Make It: Sketching Precise Drawings for Laser Cutting. In CHI 2012 Extended Abstracts, pp. 1079-1082.

[13] Mueller S., Lopes P., Baudisch P. Interactive Construction: Interactive Fabrication of Functional Mechanical Devices. In Proceedings of UIST 2012, pp. 599-606.

[14] Mueller S., Kruck B., Baudisch P. LaserOrigami: Laser-Cutting 3D Objects. To appear in CHI 2013.

[15] Willis K., Xu C., Wu K.-J., Levin G., Gross M. Interactive Fabrication: new interfaces for digital fabrication. International Conference on Tangible, Embedded and Embodied Interaction (TEI), 2011, pp. 69-72. 
[16] Saul G., Lau M., Mitani J., Igarashi T. SketchChair: An All-in-one Chair Design System for End Users.

International Conference on Tangible, Embedded and Embodied Interaction (TEI), 2011, pp. 73-80.

[17] Weichel C., Lau M., Gellersen H. Enclosed: A Component-Centric Interface for Designing Prototype Enclosures. International Conference on Tangible, Embedded and Embodied Interaction (TEI), 2013.

[18] Oh Y., Johnson G., Gross M., Do E. The designosaur and the furniture factory: simple software for fast fabrication. International Conference on Design Computing and Cognition, 2006, pp. 123-140.

[19] Lau M., Saul G., Mitani J., Igarashi T. Modeling-inContext: user design of complementary objects with a single photo. ACM Symposium on Sketch-Based Interfaces and Modeling (SBIM), 2010, pp. 17-24.

[20] Mellis D. and Buechley L. Case studies in the personal fabrication of electronic products. Proceedings of the Designing Interactive Systems Conference (DIS), 2012, pp. 268-277. 